\title{
Severity Score as a Prognostic Factor for Management of Infections of Odontogenic Origin, a Study of 100 Cases
}

\author{
Roman Mirochnik $^{1 *}$, Shareef Araidy ${ }^{1 *}$, Victoria Yaffe ${ }^{1}$, Imad Abu El-Naaj ${ }^{1,2}$ \\ ${ }^{1}$ Oral and Maxillofacial Surgery Department, "Baruch Padhe” Medical Center, Poria, Israel \\ ${ }^{2}$ Bar Ilan University, Israel \\ Email: roman.m972@gmail.com
}

How to cite this paper: Mirochnik, R., Araidy, S., Yaffe, V. and El-Naaj, I.A. (2017) Severity Score as a Prognostic Factor for Management of Infections of Odontogenic Origin, a Study of 100 Cases. Open Journal of Stomatology, 7, 25-34.

http://dx.doi.org/10.4236/ojst.2017.71002

Received: September 17, 2016

Accepted: January 3, 2017

Published: January 6, 2017

Copyright $\odot 2017$ by authors and Scientific Research Publishing Inc. This work is licensed under the Creative Commons Attribution International License (CC BY 4.0).

http://creativecommons.org/licenses/by/4.0/

\begin{abstract}
Purpose: The main objective of the current study is to determine whether it is possible to correlate the longevity of the hospitalization period (LOS) to efficacy of surgical treatment regime and severity scoring. Materials and Methods: A total of 100 patients met our inclusion criteria. All patient records, including results of hematologic and biochemical parameters, were recorded. The patients were later subcategorized further according to a severity score ("Low, Moderate, Severe") of their main facial space involvement. The main analysis of the study is a regression analysis model; all the variables (sex, age, CRP, white blood cell count, fever, space, and etiology) were stratified according to the overall hospital stay. A crosstab comparison was performed next; the variables were categorized and combined with hospital stay, and then entered in Spearman's rank correlation coefficient or Spearman's rho $(\rho)$, 2 -tailed (t) Test, and regression equation. The significance level was set at $p<$ 0.05 . Statistical analyses were conducted using SPSS version 23. Results: The most prevalent anatomical space infection was vestibular space abscess or cellulitis $33 \%$, followed by an infraorbital space abscess or cellulitis $17 \%$. Most commonly involved teeth are lower molars with $43 \%$ of the total, upper central sixth with $20 \%$ and upper molars with $10 \%$; mandibular origin was found to be the cause in $54 \%$. The regression equation showed no linear relation between CRP with the overall hospital stay $(p>0.05)$. No systemic temperature values were found to be correlated to any space involved or LOS. Logrank chi-square effect tests indicated only a significant effect of severity, $p=$ 0.00016 . The "Moderate \& Severe" group compared to the "Low" group had a longer median LOS, 4.5 ( 2 to 8 ) vs 3 ( 1 to 8 ) respectively. Conclusion: The findings of this study have shown severity scoring to be statistically significant parameter in LOS prediction.
\end{abstract}




\section{Keywords}

CRP, Odontogenic Infection, Dental Abscess, C-Reactive Protein

\section{Overview and Introduction}

Acute dental infections are a common cause of outpatient emergency visits to the maxillofacial department; classic signs of infection such as "Rubor", " $T u$ mor", "Calor", "Dolor" and "Functio Laesa" are present to some degree in nearly all patients [1] [2]. Unknowingly, they are at a potentially life threatening situation due to the anatomical connectivity of one anatomic space to the other [1].

In the preantibiotic era, severe odontogenic infections were associated with high mortality rates, ranging from $10 \%$ to $40 \%$; yet, in nowadays surgical practice implementing modern antibiotics mortality rates have been significantly reduced [3] [4].

Some attempts have been made to utilize CRP levels as an inflammatory prognostic factor in management of infections of odontogenic origin, its rapid rise and falls makes it a much more sensitive predictor than ESR and WBC count [5] [6] [7] [8] [9]. CRP has shown to be able to discriminate bacterial and viral infections and gauge of inflammatory response [10] [11].

A large scale prospective study has shown that in the U.S. alone, over a period of 24 months $13 \%$ of adult patients have sought for emergency treatment of acute dental pain and/or infections of odontogenic origin. Dental abscesses account for $47 \%$ of all dental-related attendances at pediatric emergency rooms [2].

\subsection{Etiology of Acute Odontogenic Infections}

Most common etiological factors of odontogenic infections are periapical lesions $66 \%-70 \%$ and dental caries $33 \%-80 \%$, other local infection causative factors are pricoronitis, alveolar osteitis, periodontitis and odontogenic and non-odontogenic cystic lesions.

Post operative local infections are a common site especially after mandibular molars extractions, it constitutes for more than $50 \%$ of all post operative complications [12].

\subsection{Signs and Symptoms}

Severe odontogenic infections of maxillofacial origin present common signs and symptoms, other than the usual signs of infection, one may present with trismus, dysphagia, fever, pain, swelling and respiratory distress, orbital cellulitis and other [12].

\subsection{Local Pattern of Infection Spread}

General spread of odontogenic infections is towards the lowest point of resis- 
tance, its course is usually determined by two main factors: 1) Surrounding bone thickness 2) Muscle attachments.

Odontogenic infections may spread to deeper spaces, potentially leading to life threatening situations due to air way compromise [12].

\subsection{Surgical Procedure}

Our treatment protocol includes an incision and drainage under local anesthetics by Lidocaine $2 \%$ 1:100,000 Epinephrine.

Pathogenic teeth are extracted, abscess is drained by an intra/extra oral approach according to its location and a rubber drainage is fixed for the period of two consecutive admission days, antibiotics are admitted by $\mathrm{PO} / \mathrm{IV}$ route.

\subsection{Antimicrobial Therapy}

Penicillins are most commonly used, they are considered to be the drug of choice for treatment of acute odontogenic infections. They are cheap, well tolerated, have relative low incidence of immune responses, and they are widely available. In our practice Amoxicilin in combination with clavulanate acid is first line antibiotics, admitted by IV route ( $1 \mathrm{gr} \times 3 /$ Day) [12].

\subsection{Imaging}

Although different imaging techniques are available, a CT scan is considered to be gold standard (Figure 1, Figure 2). Ultrasonography has been suggested as a possible modality for imaging of infections; it is becoming increasingly available in outpatient settings, its noninvasive nature, lack of radiation and low cost, makes it an attractive option, however, so far it has not been successful in detecting deep fascial space infections.

\subsection{Main Space Involvement and Severity Scoring (Figure 3, Figure 4)}

Anatomic spaces of the head and neck are scored by their severity according to the potential compromise of air way and other vital structures, such as, heart, mediastinum and CNS.

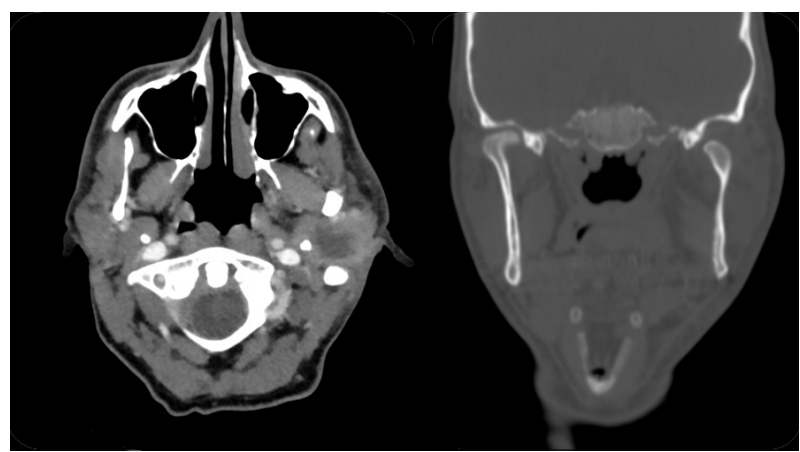

Figure 1. Axial CT scan demonstrating an acute odontogenic infection occupying the Lt. Infratemporal space region. Coronal CT scan demonstrating a pain controlled dislocation of lt. condyle. 
Low grade severity includes the Buccal, Vestibular and Subperiosteal spaces as they do not compromise vital structures or air way. Moderate grade severity includes the masticatory spaces which can be further sub classified to submasseteric, pterygomandibular and superficial and deep temporal spaces, and perimandibular spaces which can be further subclassified to submandibular, submental and sublingual spaces, those account to a moderate severity due to their access to airway and trismus potential.

High grade severity includes spaces in which swelling can directly obstruct or deviate the airway or endanger vital structures, this group includes lateral and retro pharyngeal spaces and mediastinum [10].

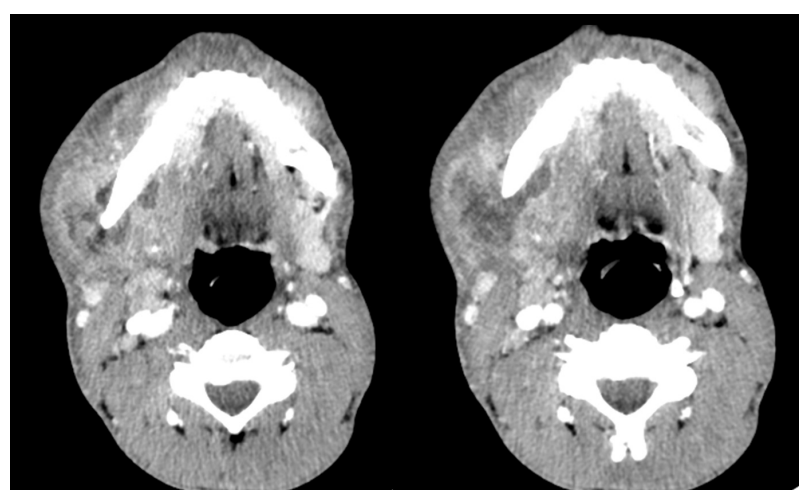

Figure 2. Axial CT scans demonstrating acute odontogenic infections occupying the Rt. Submasseteric and Pterygomandibular spaces.

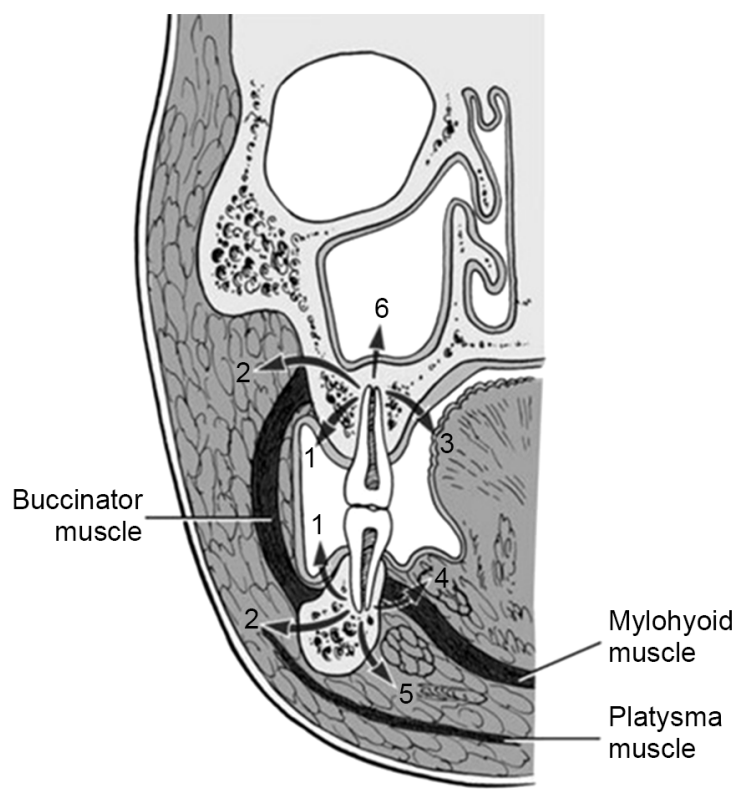

Figure 3. Odontogenic infection spread patterns. As infection erodes through bone, it can express itself in a variety of places, depending on thickness of overlying bone and relationship of muscle attachments to site of perforation. This illustration notes six possible locations: vestibular abscess (1), buccal space (2), palatal abscess (3), sublingual space (4), submandibular space (5), and maxillary sinus (6). (Adapted from Flint PW Haughey BH, Lund VJ et al., editors: Cummings otolaryngology: Head and neck surgery, ed 5, Philadelphia, PA, 2010, Mosby.) 


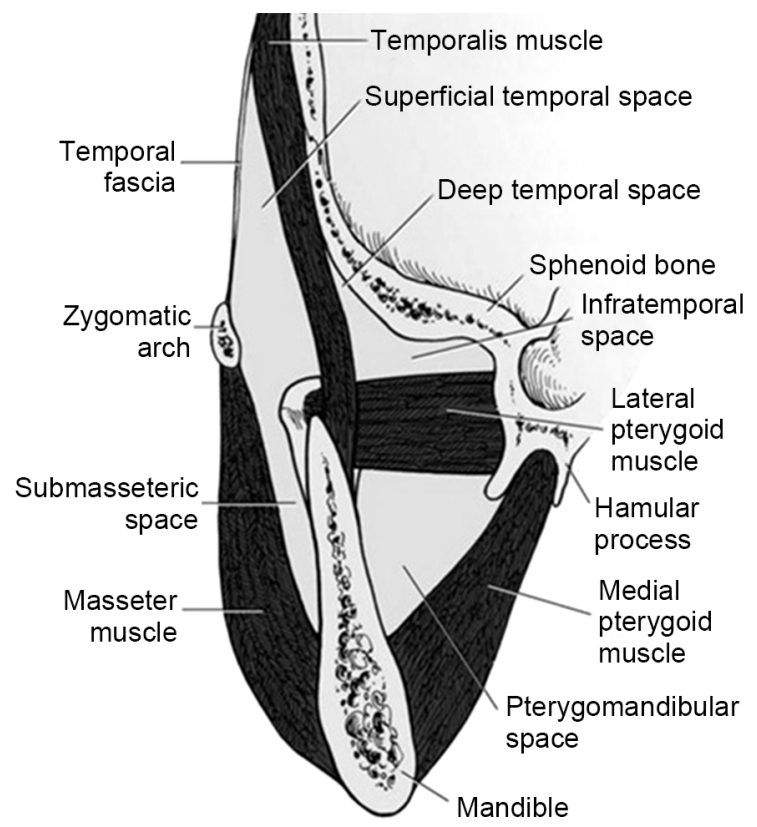

Figure 4. The superficial and deep temporal spaces are separated from each other by the temporalis muscle. The lateral pterygoid muscle divides the pterygomandibular space from the infratemporal portion of the deep temporal space, and the zygomatic arch divides the submasseteric space from the superficial temporal space. (Adapted from Flint PW Haughey BH, Lund VJ et al., editors: Cummings otolaryngology: Head and neck surgery, ed 5, Philadelphia, PA, 2010, Mosby.)

\section{Materials and Methods}

\subsection{Purpose}

The main objective of the current study is to determine whether it is possible to correlate the longevity of the hospitalization period (LOS) to efficacy of surgical treatment regime and severity scoring.

The criteria of inclusion for this study are:

- Age over 18 years.

- Complete medical records.

- Patient suffering from an infection of an odontogenic origin.

The criteria of exclusion for this study are:

- Age under 18 years.

- Patients suffering from infections of other regions other than the oral cavity were excluded from the study, as well as patients suffering from HIV/AIDS, neoplasms, hepatitis, lupus, inflammatory bowel diseases, tuberculosis, respiratory and urinary infections.

Study subjects were patients who visited the emergency department at the "Padeh" Poria Medical Center which is a level $2 b$ trauma center with over 80,000 annual patients, for treatment of acute odontogenic infections of the head and neck area.

A total of 137 patients requiring hospitalization were treated between October 2014 and June of 2015 by the "Department of Oral and Maxillofacial Surgery", 100 have met our inclusion criteria. 
An examination following a standard protocol of the "Maxillofacial Department" was performed, dental radiographs were taken to assist the diagnostic procedure, a contrast enhanced computer tomography was performed upon need.

Admission criteria were swelling of the face or neck area suggesting an abscess or a cellulitis and one or more of the following: temperature above $38.3^{\circ} \mathrm{C}$, white blood cell (WBC) count greater than $10.8 \times 10^{3} / \mathrm{L}$, CRP levels greater than $10 \mathrm{mg} / \mathrm{l}$, airway compromise, trismus, lower eye-lid involvement and dysphagia [10].

Antecubital venous blood was drawn on admission and on the day of release. Laboratory values analyzed included C-reactive protein (CRP) concentrations (reference range, 1 to $10 \mathrm{mg} / \mathrm{L}$ ).

Body temperature was measured orally at least twice daily, mean values and standard deviations of the laboratory values were calculated.

\subsection{Statistical Analysis}

The clinical data recorded included medical, social, and behavioral factors such as age, gender, ethnicity, underlying systemic illnesses, smoking habits, body mass index, previous dental procedures, antibiotic therapy, symptoms on admission, delay in seeking medical therapy, and site of the infection.

All patient records, including results of hematologic and biochemical parameters, were recorded.

The patients where later subcategorized further according to a severity score ("Low, Moderate, Severe") of their main facial space involvement.

The main analysis of the study is a regression analysis model; all the variables (sex, age, CRP, white blood cell count, fever, space, and etiology) were stratified according to the overall hospital stay. A crosstab comparison was performed next; the variables were categorized and combined with hospital stay, and then entered in Spearman's rank correlation coefficient or Spearman's rho $(\rho)$, 2-tailed ( $\mathrm{t}$ ) Test, and regression equation. The significance level was set at $p<$ 0.05. Statistical analyses were conducted using SPSS version 23 .

\section{Results}

A total of 137 patients who were diagnosed clinically and radiologically with maxillofacial infections were admitted and hospitalized in the Maxillofacial Surgery Department, Baruch Padeh Medical Center, Poriya, Israel. Only patients who met the inclusion criteria were included in the study.

100 patients, 49 females mean age of 37.8 years and 51 males mean age of 36.1 years were evaluated. Most commonly involved spaces, their average longevity stay and average CRP values on admission are as presented in (Table 1).

Overall patient management was comparable among all the patients, all patients were treated by similar surgical approaches and antibiotic therapy.

The most prevalent anatomical space infection was vestibular space abscess or cellulitis $33 \%$, followed by an infraorbital space abscess or cellulitis $17 \%$, (Table 1). 
Table 1. Data accumulation.

\begin{tabular}{|c|c|c|c|c|c|c|c|c|c|}
\hline Space & Severity & & $\begin{array}{l}\text { No. } \\
\text { Patient }\end{array}$ & & $\begin{array}{c}\text { CRP On } \\
\text { Admission }\end{array}$ & $\begin{array}{l}\text { CRP On } \\
\text { Release }\end{array}$ & $\begin{array}{l}\text { Admission } \\
\text { Days }\end{array}$ & $\begin{array}{c}\text { Systemic } \\
\text { Temp }\end{array}$ & Treatment \\
\hline & & Total & M & $\mathrm{F}$ & & & & & \\
\hline Vestibular Space & Low & 33 & 17 & 16 & 55.68 & 40.2 & 2.96 & 37.1 & $\begin{array}{c}\text { Extraction, Drainage \& } \\
\text { IV. Antibiotics }\end{array}$ \\
\hline Infraorbital Space & Low & 17 & 6 & 11 & 77.3 & 44.6 & 2.88 & 37.2 & $\begin{array}{c}\text { Extraction, Drainage \& } \\
\text { IV. Antibiotics }\end{array}$ \\
\hline Buccal Space & Low & 1 & 1 & - & 52.5 & 35 & 3 & 36.6 & $\begin{array}{l}\text { Extraction, Drainage \& } \\
\text { IV. Antibiotics }\end{array}$ \\
\hline Palatinal Space & Low & 1 & 1 & - & 12.4 & 7 & 4 & 36.7 & $\begin{array}{c}\text { Extraction, Drainage \& } \\
\text { IV. Antibiotics }\end{array}$ \\
\hline Inflamed Cysts & Low & 8 & 5 & 3 & 46.2 & 27.6 & 5 & 37.2 & $\begin{array}{c}\text { Extraction, Drainage \& } \\
\text { IV. Antibiotics }\end{array}$ \\
\hline Sum. & & 60 & 30 & 30 & & & & & \\
\hline Average & & & & & 48.82 & 30.88 & 3.57 & 36.96 & \\
\hline Lingual Space & Moderate & 3 & 2 & 1 & 78.4 & 63.3 & 2.66 & 37.3 & $\begin{array}{l}\text { Extraction, Drainage } \\
\text { \& IV. Antibiotics }\end{array}$ \\
\hline Pterygomandibular Space & Moderate & 8 & 4 & 4 & 81.45 & 50.8 & 5.62 & 37.1 & $\begin{array}{l}\text { Extraction, Drainage } \\
\text { \& IV. Antibiotics }\end{array}$ \\
\hline Submasseteric Space & Moderate & 2 & 1 & 1 & 85.35 & 67.5 & 6.5 & 37.3 & $\begin{array}{l}\text { Extraction, Drainage } \\
\text { \& IV. Antibiotics }\end{array}$ \\
\hline Infratemporal Space & Moderate & 6 & 2 & 4 & 63.4 & 30.4 & 6.8 & & $\begin{array}{l}\text { Extraction, Drainage } \\
\text { \& IV. Antibiotics }\end{array}$ \\
\hline Submandibular Space & Moderate & 1 & 1 & - & 100 & 50.7 & 7 & 37.2 & $\begin{array}{l}\text { Extraction, Drainage } \\
\text { \& IV. Antibiotics }\end{array}$ \\
\hline Pericoronitis & Moderate & 7 & 4 & 3 & 46.25 & 27.9 & 3.42 & 37.08 & $\begin{array}{l}\text { Extraction, Drainage } \\
\text { \& IV. Antibiotics }\end{array}$ \\
\hline Post Operative Abscess & Moderate & 8 & 3 & 5 & 57 & 48 & 3.6 & 37.2 & $\begin{array}{l}\text { Extraction, Drainage } \\
\text { \& IV. Antibiotics }\end{array}$ \\
\hline Maxillary Sinusitis & Moderate & 3 & 1 & 2 & 32.26 & 27.9 & 4.3 & 37.4 & $\begin{array}{l}\text { Extraction/Closure of } \\
\text { OAF \& IV. Antibiotics }\end{array}$ \\
\hline Sum. & & 38 & 18 & 20 & & & & & \\
\hline Average & & & & & 68.01 & 45.81 & 4.98 & 37.2 & \\
\hline Lateral Pharyngeal Space & High & 2 & 1 & 1 & 75 & 11.6 & 5 & 37.05 & $\begin{array}{l}\text { Extraction, Drainage } \\
\text { \& IV. Antibiotics }\end{array}$ \\
\hline Sum. & & 2 & 1 & 1 & & & & & \\
\hline Average & & & & & 75 & 11.6 & 5 & 37.05 & \\
\hline
\end{tabular}

The records were further subcategorized according to main anatomic space involvement and its severity score ("Low, Moderate and High").

60 patients were classified as of low severity score (LSS), 38 of moderate severity (MSS) and only 2 as high severity (HSS).

Most commonly involved teeth are lower molars with $43 \%$ of the total, upper 
central sixth with $20 \%$ and upper molars with $10 \%$, mandibular origin was found to be the cause in $54 \%$.

Wisdom teeth were found to be the source of infection with $29 \%$ of the cases, upper central/lateral incisors and canines were found to be the source in $20 \%$ of the cases.

The regression equation showed no linear relation between CRP with the overall hospital stay $(p>0.05)$. Regression test supported the previous results, and showed no significance in the CRP in predicting length of hospitalization stay $(p>0.05)$. No systemic temperature values were found to be correlated to any space involved nor severity scoring.

Log-rank chi-square effect tests indicated only a significant effect of severity, $p$ $=0.00016$, the "Moderate \& Severe" group compared to the "Low" group had a longer median LOS, 4.5 ( 2 to 8 ) vs 3 ( 1 to 8 ) respectively.

\section{Discussion}

Attempts been made to use CRP as an inflammatory prognostic factor with odontogenic infections of the head and neck area.

Several studies have indicated CRP to be an effective predictor to hospital stay, yet, we were unable to support this premises in our study as it showed no statistical significant correlating between CRP levels on admission and longevity of stay, the rapid rise and fall of CRP with the inflammatory process makes it a higly sensitive indicator of inflammatory process but as we have witnessed surgical intervention also results with a marked elevation in CRP levels, thus resulting an overlapping high CRP level. Mean hospital longevity stay due to acute odontogenic infections of head and neck area is found to be ranging from 3.69 to 8.27 consecutive days, our study have showed a mean of 3.84 days.

Odontogenic infection of head and neck area are commonly single space infections, multiple space involvement is rare, most commonly involved spaces are vestibular space abscess corresponding to one third of the cases, second most common space is infraorbital space abscess corresponding to $17 \%$ of all cases, involvement of paraphryngeal space abscess is rare and corresponds to $2 \%$.

Out of the 30 subjects presenting with CRP levels of 100 and higher, $26 \%$ were suffering from infraorbital space infections, this may be attributed to lower eye lid involvement and preseptal cellulitis formation.

Underlying medical conditions, highly increased inflammatory markers and complications have been shown related to prolong hospital stay. Patients suffering from odontogenic infection of mandibular teeth origin have shown relatively longer hospital stay compared with infections of maxillary teeth origin.

Our study has shown a clear correlation between clinical severity scoring and length of stay $(p=0.00016)$.

\section{Conclusions}

Within the limitations of this study our findings have shown that proper clinical evaluation, assessment and severity scoring are of higher prognostic value in re- 
spect to LOS than other proposed indicators such as CRP which has shown to be a non-significant parameter.

A larger amount of high severity score patients is needed to withstand proper statistical analysis.

\section{Acknowledgements}

The authors declare to have no conflicts of interest.

\section{Ethics Statement/Confirmation of Patient Permission}

Ethics approval not required. Patient permission obtained.

\section{References}

[1] Sharma, A., Giraddi, G., Krishnan, G. and Shahi, A.K. (2012) Efficacy of Serum Prealbumin and CRP Levels as Monitoring Tools for Patients with Facial Space Infections of Odontogenic Origin: A Clinicobiochemical Study. National Journal of Maxillofacial Surgery, 3, 148-151. https://doi.org/10.4103/0975-5950.111369

[2] Ylijoki, S., Suuronen, R., Jousimies-Somer, H., Meurman, J.H. and Lindqvist, C. (2001) Differences between Patients with or without the Need for Intensive Care Due to Severe Odontogenic Infections. Journal of Oral and Maxillofacial Surgery, 59, 867-872. https://doi.org/10.1053/joms.2001.25017

[3] Pepys, M.B. and Hirschfield, G.M. (2003) C-Reactive Protein: A Critical Update. Journal of Clinical Investigation, 111, 1805-1812. https://doi.org/10.1172/JCI200318921

[4] Ren, Y.F. and Malmstrom, H.S. (2007) Rapid Quantitative Determination of CReactive Protein at Chair Side in Dental Emergency Patients. Oral Surgery, Oral Medicine, Oral Pathology, Oral Radiology, and Endodontology, 104, 49-55. https://doi.org/10.1016/j.tripleo.2007.01.007

[5] Iizuka, T. and Lindqvist, C. (1991) Changes in C-Reactive Protein Associated with Surgical Treatment of Mandibular Fractures. Journal of Oral and Maxillofacial Surgery, 49, 464-467. https://doi.org/10.1016/0278-2391(91)90168-L

[6] Jundt, J.S. and Gutta, R. (2012) Characteristics and Cost Impact of Severe Odontogenic Infections. Oral Surgery, Oral Medicine, Oral Pathology, Oral Radiology, and Endodontology, 114, 558-566. https://doi.org/10.1016/j.00oo.2011.10.044

[7] Khan, M.H., Smith, P.N., Rao, N. and Donaldson, W.F. (2006) Serum C-Reactive Protein Levels Correlate with Clinical Response in Patients Treated with Antibiotics for Wound Infections after Spinal Surgery. Spine Journal, 6, 311-315. https://doi.org/10.1016/j.spinee.2005.07.006

[8] Margheritini, F., Camillieri, G., Mancini, L. and Mariani, P.P. (2001) C-Reactive Protein and Erythrocyte Sedimentation Rate Changes Following Arthroscopically Assisted Anterior Cruciate Ligament Reconstruction. Knee Surgery, Sports Traumatology, Arthroscopy, 9, 343-345. https://doi.org/10.1007/s001670100232

[9] Bilgen, O., Atici, T., Durak, K., Karaeminogullari and Bilgen, M.S. (2001) C-Reactive Protein Values and Erythrocyte Sedimentation Rates after Total Hip and Total Knee Arthroplasty. Journal of International Medical Research, 29, 7-12. https://doi.org/10.1177/147323000102900102

[10] Miloro, M., Ghali, G.E., Larsen, P. and Waite, P. (2012) Peterson's Principles of "Oral and Maxillofacial Surgery". 3rd Edition, Shelton Connecticut, People's Medical Publishing House, 841-861. 
[11] Duclos, T.W. (2000) Function of C-Reactive Protein. Annals of Medicine, 32, 274278. https://doi.org/10.3109/07853890009011772

[12] Gronholm (2010) Severe Odontogenic Infections. Dissertation, University of Helsinky, Helsinky.

Submit or recommend next manuscript to SCIRP and we will provide best service for you:

Accepting pre-submission inquiries through Email, Facebook, LinkedIn, Twitter, etc. A wide selection of journals (inclusive of 9 subjects, more than 200 journals)

Providing 24-hour high-quality service

User-friendly online submission system

Fair and swift peer-review system

Efficient typesetting and proofreading procedure

Display of the result of downloads and visits, as well as the number of cited articles

Maximum dissemination of your research work

Submit your manuscript at: http://papersubmission.scirp.org/

Or contact ojst@scirp.org 